\title{
GEOMODELAGEM COM APRENDIZES DE UMA ESCOLA CICLADA
}

\author{
Paula Aguiar da Silva - paulaasmini@ yahoo.com.br \\ Programa de Pós Graduação em Ensino de Matemática - UFRGS
}

\section{Resumo}

Em uma escola ciclada, as turmas de progressão abrigam alunos que não possuem escolaridade compatível com o ciclo da sua idade. Este artigo apresenta uma proposta de trabalho com uma turma de progressão do terceiro ciclo do Ensino Fundamental usando o software Google SketchUp. A iniciativa visa indagar a viabilidade de uso de softwares que não foram elaborados para o ensino-aprendizagem de matemática nas salas de aula dessa disciplina, explorando a construção de modelos tridimensionais das casas dos alunos. Além disso, busca encontrar uma didática condizente com a proposta pedagógica da escola, que se adeque à turma de progressão, no sentido de atender as necessidades de aprendizagem de cada estudante a partir da Teoria dos Campos Conceituais de Vergnaud.

Palavras-chave: Aprendizagem, Ciclos de Formação, SketchUp, Tecnologias

Geo-modeling with learners of Cycles of Education

\begin{abstract}
In a Cycles of Education, classes of progression house students who have no schooling compatible with the cycle of their age. This article presents a proposal to work with a group of progression of the third cycle of elementary school using the Google SketchUp software. The initiative aims to investigate the feasibility of use of software that are not designed for teaching and learning of mathematics in the classrooms of this discipline, exploring the construction of three-dimensional models of the homes of students. Moreover, attempts to find a teaching consistent with the pedagogical school, which fits to the class progression, in order to meet the learning needs of each student from the Vergnaud's Conceptual Field Theory.
\end{abstract}

Keywords: Learning, Cycles of Education, SketchUp, Technology.

\section{A Escola de Ensino Fundamental Paulo Freire}

A escola Paulo Freire, localizada no município de Alvorada/RS, é, atualmente, a única escola ciclada da rede municipal de Alvorada que possui anos finais do Ensino Fundamental. Criada em 1998 com uma proposta pedagógica diferenciada, baseada nos pilares da construção dos Ciclos de Formação ${ }^{i}$, o planejamento é proposto através de Pesquisa Participante, realizada de 2 em 2 anos com a comunidade escolar.

Cabe registrar neste espaço um diferencial importante da escola: o sistema de avaliação adotado é parecer descritivo, que busca evidenciar os avanços cognitivos dos alunos, detalhando as competências desenvolvidas por eles ao longo dos trimestres letivos. Neste âmbito, percebe-se uma postura consciente dos alunos frente ao processo de ensino aprendizagem, quando não precisam se apegar a uma nota adquirida ao findar de cada etapa do processo de avaliação. Toda e qualquer atividade realizada por eles é percebida com importância para o crescimento individual, sem ser quantificada dentro do todo. Por este motivo, acredito que a proposta pedagógica da escola e o sistema de avaliação propiciam ao aluno uma significação da avaliação diferenciada, que não é 
centrada em resultados numéricos, mas que reconhece o processo de construção do conhecimento como subjetivo, complexo e de difícil quantificação, valorizando o desenvolvimento integral do aluno. Sendo assim, na escola Paulo Freire o aluno deixa de evidenciar o resultado numérico nota e passa a ter consciência e responsabilidade sobre seu processo de aprendizagem quando internaliza que cada ação pedagógica tem por objetivo único a sua aprendizagem.

O trabalho aqui apresentado foi realizado com uma turma de progressão do terceiro ciclo do ensino fundamental. Sobre estas turmas:

\begin{abstract}
"Serão organizadas, em cada Ciclo, (...) visando atender os educandos com defasagem entre sua faixa etária e a escolaridade, realizando-se aí um trabalho direcionado para a superação das dificuldades e lacunas apresentadas pelos educandos que estiverem nesta condição. (...) terão uma organização de tempo-ano diferente da organização ano-Ciclo. Isto significa que os estudantes que estiverem nas Turmas de Progressão poderão avançar para o ano seguinte a qualquer momento (...).” (Nery, Rocha, 1999, p.22)
\end{abstract}

Cabe ao professor destas turmas então, atender as necessidades dos educandos em sua heterogeneidade no processo de ensino aprendizagem, visto que cada deles possui alguns conceitos e conteúdos construídos e dificuldades anteriores àquelas pertencentes ao terceiro ciclo (a saber $7^{\circ}, 8^{\circ}$ e $9^{\circ}$ anos do Ensino Fundamental) que precisam ser resgatadas. Além disso, dentro desta proposta a ação pedagógica do professor precisa ser interdisciplinar e contextualizada.

Princípio 30 .- Interdisciplinaridade como proposta de trabalho do professor, gerando uma ação pedagógica onde as disciplinas não apenas somem seus esforços, e sim trabalhem para a construção de conceitos-conteúdos como meio e não como fim, contemplando educação e trabalho, dimensões para a vida, poder, formação, força de trabalho, cidadania, realização pessoal, valorização do ser humano." (SMED, 2000)

\title{
2. Software gratuito
}

Com o avanço crescente e exponencial das tecnologias digitais e as iniciativas públicas do nosso país em inclusão digital, é grande a demanda de softwares voltados para o ensino.

Sabemos que muitas vezes, no meio educacional público é difícil a aquisição de materiais específicos para uma determinada área ou em uma iniciativa inovadora e ainda não testada, cujos resultados são desconhecidos. Nesse sentido, o uso do Google Sketchup é viável para quebrar barreiras quanto ao novo e propor uma introdução da geomodelagem na escola sem a necessidade de se depender de recursos financeiros destinados para isto.

O Google SketchUp é um software gratuito criado para o trabalho de profissionais das áreas da engenharia, arquitetura, design e modelagem, sendo usado inclusive por desenvolvedores de jogos e softwares que precisam de modelagem em três dimensões. Porém, a empresa também vê no software a possibilidade de sua implementação nas escolas e auxílio à educação.

O Google acredita no apoio à educação. Nosso compromisso é oferecer licenças de software e recursos de baixo custo ou até mesmo gratuitos aos estudantes, educadores e instituições de ensino. Acreditamos que o SketchUp tem um papel importante em cada sala de aula, dormitório de faculdade ou laptop de estudante do planeta. Afinal, nós vivemos em um mundo 
tridimensional. Então, por que não começamos a pensar e a ensinar dessa forma?" (Google, 2010)

Além da verão gratuita do software, chamada apenas de SketchUp, há a venda a versão SketchUP Pro, que como o nome sugere é voltado para uso profissional de quem trabalha com modelagem 3D.

\section{A inversão da lógica da aprendizagem no uso do software}

Sabemos a partir de Vergnaud (1993) que os campos conceituais são um conjunto informal e heterogêneo de problemas, situações, conceitos, relações, estruturas, conteúdos e operações de pensamento conectados uns aos outros e, provavelmente entrelaçados durante o processo de aquisição. Nesse sentido, buscamos com o uso da geomodelagem proporcionar aos educandos algumas destas diferentes situações e problemas que possibilitem a aquisição de conceitos de matemática.

$\mathrm{O}$ uso do software e suas diversas opções possibilita ao professor abordar e problematizar diferentes conceitos de matemática a partir da construção que está sendo realizada pelo aluno. Tal possibilidade aliada às diferentes intervenções serve perfeitamente aos requisitos necessários para um trabalho a ser desenvolvido com uma turma de progressão. Lembremos que na turma de progressão, diferentes são as demandas dos alunos, pois não possuem escolaridade equivalente ao ciclo correspondente a sua idade. Sendo assim, cada aluno possui dificuldades e necessidade particulares que devem ser atendidas pelo professor.

Como qualquer outro recurso, este também precisa da intervenção do professor, para realmente explorar suas utilidades e eficácias perante o ensino de matemática. A simples presença dessa tecnologia não garante qualidade de ensino e nem da concretização dos conceitos a serem explorados. (Monzon, 2010. p.3)

Como ressalta Monzon, ainda assim o uso da ferramenta SketchUp tem sua potencialidade atrelada as intervenções do professor. Este deve buscar perceber nas manipulações dos alunos as suas necessidades, bem como os esquemas utilizados para aquela classe de situação dada. Desta forma, ele pode atuar provocando confrontos para que um dado procedimento seja interiorizado a ponto de se tornar um invariante no processo cognitivo do aluno.

A proposta aqui apresentada possibilita aos alunos a imposição de seus desejos e expectativas na construção e no uso do software Google SketchUp e dialoga com a didática de um professor facilitador e orientador ao invés de centralizador do processo.

Com isso, esperava-se que os alunos passassem a se interessar pela disciplina e pelas atividades a serem realizadas nela, além de que seu estudo fosse mais rico, abrangente e diversificado, que não se engessasse em qualquer currículo e que não uniformizasse ou limitasse o aprendizado dos estudantes nos conceitos que o professor oferecesse a eles.

A proposta de trabalho foi realizada como descrita a seguir. Os alunos foram apresentados ao software e suas possibilidades, e a princípio decidiram realizar uma "maquete virtual" da escola inteira. Para isso, perceberam de que era necessário realizar algumas medidas do que seria construído no SketchUp, pois segundo eles, se isso não fosse feito, tudo ia ficar "desequilibrado". A partir disso, usando trenas realizaram com o acompanhamento do professor medidas de diversos ambientes da escola, nos dois andares que ela possui. Realizaram anotações nos seus cadernos, dividindo o trabalho entre eles, para que tudo fosse mapeado. Entretanto, ao se depararem com o software 
novamente, perceberam que não seria possível dividir também o trabalho na hora de modelar o espaço escolar, pois se cada espaço da escola fosse construído por cada um deles, não conseguiriam depois unir estes espaços num único modelo. Com este conflito, surgiu entre os alunos a ideia de que então cada um poderia fazer sua própria casa, do jeito que realmente era. Sendo assim, partiram para suas casas com a tarefa de realizarem as medidas que achassem necessárias para a construção dos seus modelos. Com as anotações, surgiu a necessidade de representar os espaços das casas de alguma forma no papel e com isso as plantas baixas das casas.

\section{Software que não é "de matemática" - o que trabalha?}

Atualmente, é possível encontrar na rede um grande número de softwares voltados para o ensino-aprendizagem de matemática. Naturalmente, a elaboração e construção destes softwares parte do princípio de que ele será utilizado para o ensino de matemática, e por isso, em sua maioria, são softwares que já partem da ideia que tanto professor como aluno estão voltados para a aprendizagem de matemática apenas. $\mathrm{O}$ aluno, já consciente disso, dificilmente deposita na atividade realizada com este software desejos ou anseios pessoais de aprendizado, visto que o professor orientará a atividade a ser realizada, partindo de um currículo que deve ser visto ou de um interesse de estudo.

Um questionamento que facilmente surge é: o que é possível explorar de conceitos da área de matemática em um software que não é voltado para os estudos da disciplina? Desde o princípio do trabalho, minha expectativa era aproximar meus alunos da matemática sem que ela necessitasse estar revelada por princípio e sem que seu uso fosse antecessor a atividade realizada. $\mathrm{O}$ motivo para que isto acontecesse era muito óbvio pra mim, pois a totalidade dos alunos da turma é resistente em relação a aprender os conceitos de matemática e por algum motivo, ao longo do seu processo estudantil, passaram a acreditar que não eram capazes de aprender a disciplina. Precisava resgatar nestes alunos a autoestima e mostrar-lhes que eram capazes de aprender os conceitos da disciplina de matemática.

Além disso, como característica da turma de progressão, precisava abordar diferentes conceitos com cada um dos estudantes e tal necessidade me direcionava para o uso de um software abrangente. Neste sentido encontrei no SketchUp a possibilidade de problematizar com cada estudante algo distinto, conforme o trabalho fosse sendo desenvolvido. 


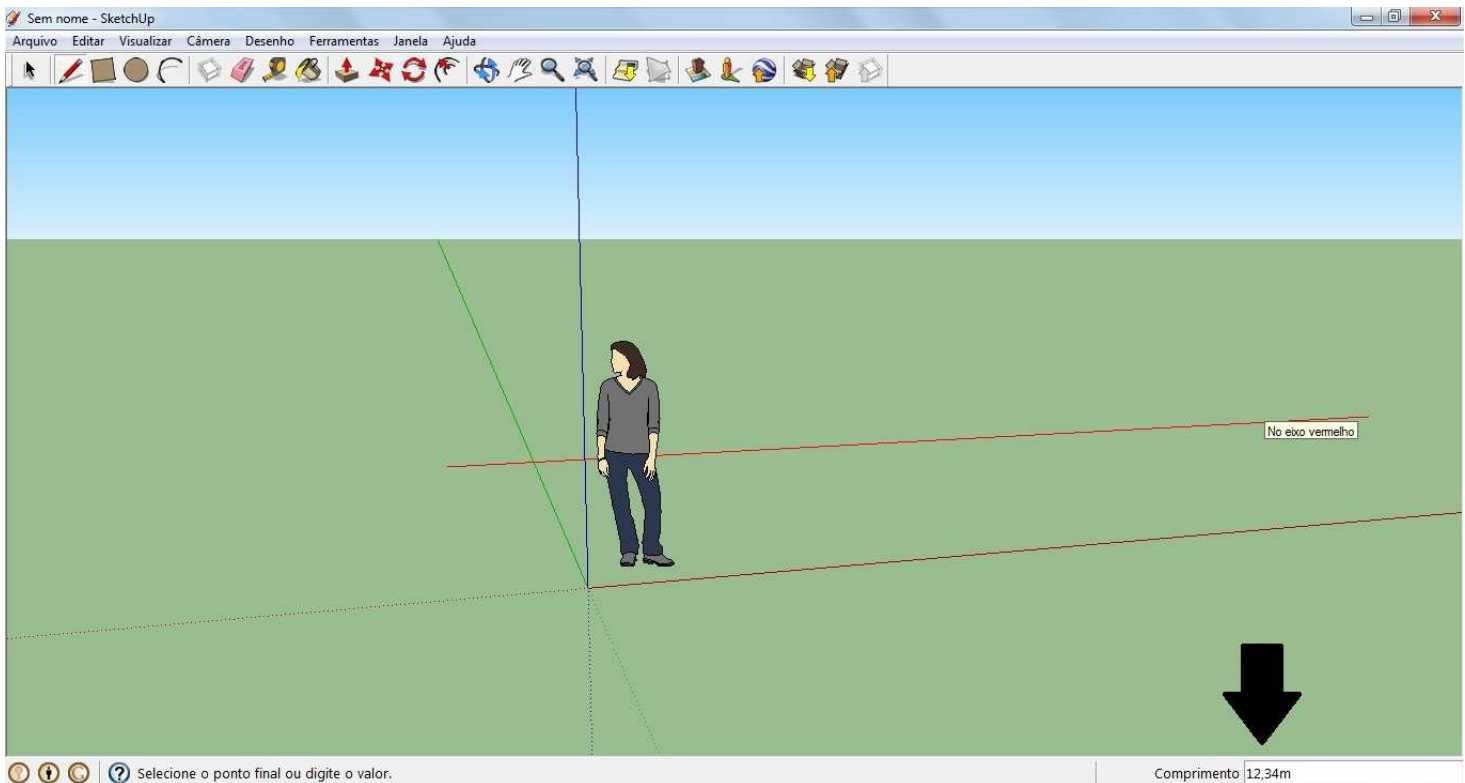

Figura 1 - Tela inicial do SkecthUp com reta paralela e unidade de medida

Ao realizar uma análise do software pude constatar que ele emprega muitos conceitos de geometria euclidiana de forma intuitiva e prática. Por exemplo, apresentado na Figura 1, onde uma reta paralela a um dos eixos ortogonais do Sistema Cartesiano é evidenciada quando apresenta a mesma cor do eixo de referência e a inscrição "no eixo vermelho" aparece. Desta forma, busquei avaliar a utilização dos conceitos de geometria seu significado no uso do software da mesma forma intuitiva que ele apresenta. Além disso, o trabalho com medidas de comprimento e área e o uso dos números racionais se fez presente na construção das casas a partir das plantas baixas construídas pelos alunos, que para isso usaram de escala em papel quadriculado como apresentado na Figura 2. 
6

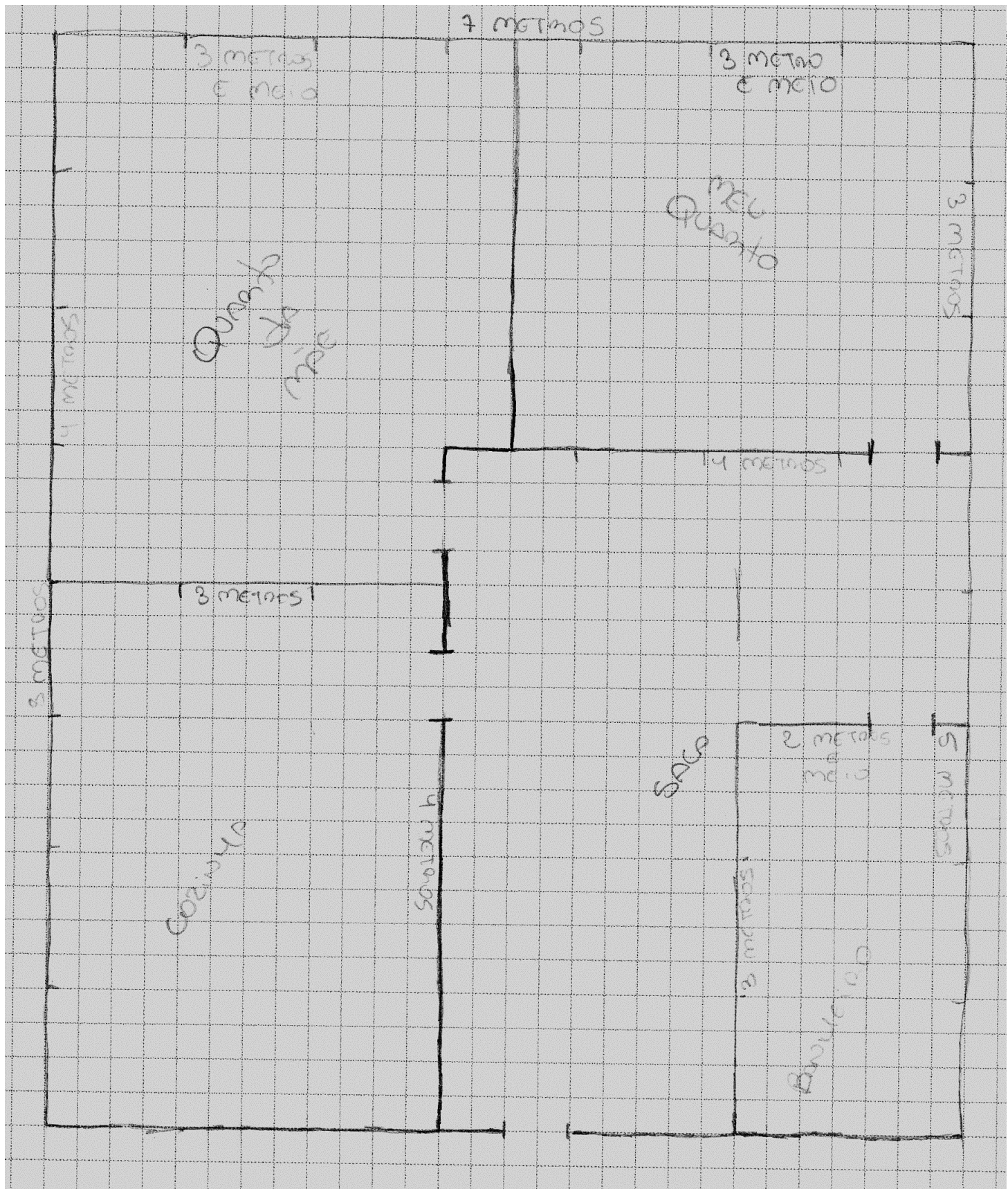

Figura 2 - Uso de escala para construção de planta baixa

Em análise preliminar do trabalho, poderíamos constatar apenas que a manipulação do software como algo lúdico representaria aparentemente algo inovador e motivacional para as aulas e matemática, que também apresentaria conceitos de matemática de forma intuitiva. Vale lembrar aqui, que a intuição é de fundamental importância para a construção do pensamento matemático, visto que possibilita a elaboração de hipóteses a serem testadas, mesmo sendo refutadas ou validadas e que é a partir disto se realizam as pesquisas.

Porém, durante o desenvolvimento do trabalho, apesar de todos os alunos terem decidido pela construção de sua própria casa, fica evidente a possibilidade de diferentes abordagens e objetivos conforme a necessidade do aluno, principalmente no enfoque pedagógico e na intervenção realizada com cada um deles. Além disso, a matemática é 
ferramenta para um objetivo que não é aprender o que o professor quer, mas desenvolver algo que é de interesse do educando.

Para isto é necessário um olhar atento do professor. A intervenção no uso do software é diferencial para o trabalho, pois a partir de uma intervenção é que será possível a problematização e construção de conceitos que estão sendo manipulados na prática durante a geomodelagem. Além disso, é preciso que o professor perceba a matemática presente em todas as etapas do processo, provocando os alunos no sentido deles se questionarem diante dos erros que acontecem. Na Figura 5 que segue, podemos notar que ao construir uma das paredes da sua casa, o aluno não utilizou paralelismo entre o topo da parede e a base, o que resultou num erro de construção.

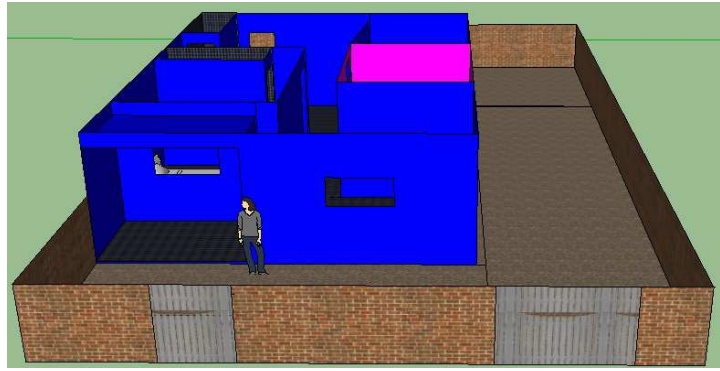

Figura 4 - Modelagem da casa com pátio

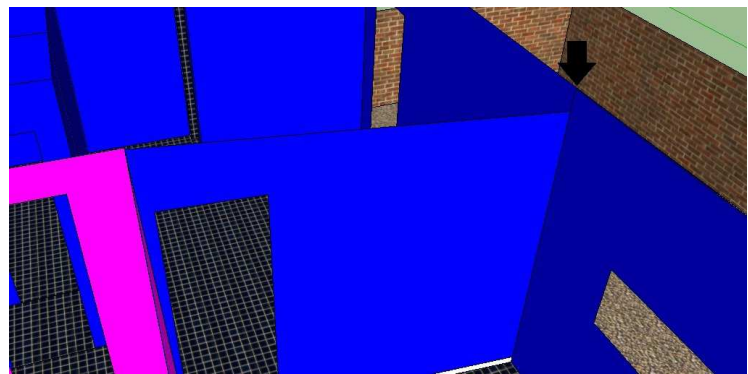

Figura 5 - Erro de construção

O aluno ao manipular seu modelo e dar a ele detalhes reais como acabamento e pintura, passa pela situação de verificar problemas, constatar erros e criar estruturas cognitivas que expliquem a causa destes problemas para corrigi-los. Geometricamente, ele precisa perceber por exemplo, que um polígono não foi fechado e por isso não pode ser preenchido, que uma reta não está paralela a outra e por isso, uma peça da sua casa ficou "torta" e assim por diante. Neste momento, o professor como mediador do processo, possui em suas mãos uma oportunidade diferenciada de construir com o aluno muitos conceitos de geomodelagem, geometria Euclidiana, operações com números decimais, unidades de medida além de proporção, razão, escala entre outros.

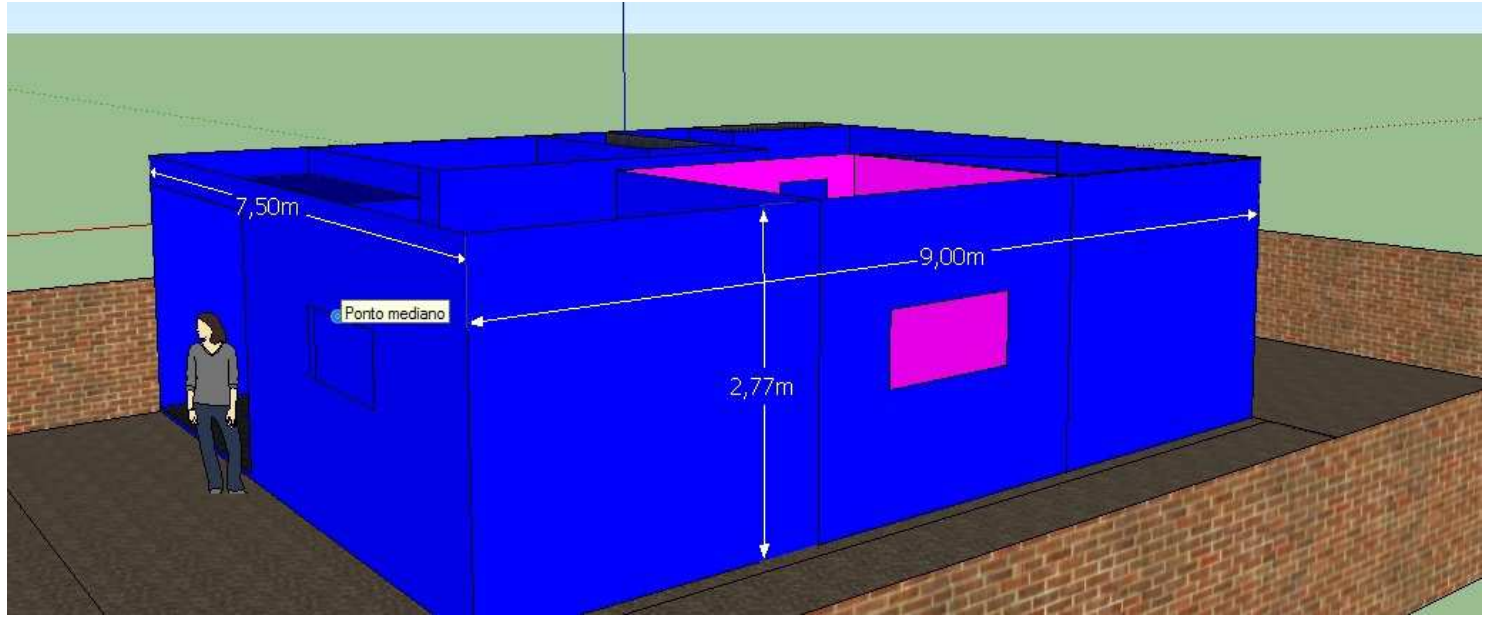

Figura 6 - Manutenção das dimensões do modelo real no modelo virtual

\section{Conclusões e resultados}


A proposta aqui apresentada se mostrou contribui no resgate da autoestima dos alunos e na apropriação do SketchUp para o aprendizado de matemática de forma mais prática, aplicada e cotidiana. A aproximação dos alunos com a matemática, usando-a como instrumento para a realização da geomodelagem, fez com que encontrasse uma resposta para a latente pergunta: "para que serve a Matemática?".

Na sala de informática, se instaurou um clima de cooperação e troca entre os alunos, onde cada descoberta nova no uso do software ou na reestruturação dos conceitos da disciplina era divulgada entre os demais com entusiasmo. Em boa parte desses momentos, os alunos recorriam aos próprios colegas na solução dos seus problemas, descobrindo novos caminhos para solucionar o entrave pedagógico encontrado.

\begin{abstract}
Ao contrário da simples reprodução de procedimentos e do acúmulo de informações, é consenso que se deve possibilitar o desenvolvimento dos alunos de forma que eles possam construir capacidades de observação e análise, de estabelecimento de relações, de comunicação e argumentação e de validação e defesa de processos e ideias, além de estimular diferentes formas de raciocínio, intuição, indução e dedução e a estimativa. (Hoffmann, 2006, p.7)
\end{abstract}

De fato, tal proposta de trabalho se adequou a proposta pedagógica da escola, ao mesmo tempo que possibilitou aos alunos o contato com a geomodelagem, uma área de estudo ainda pouco abordada nas escolas de Ensino Básico. Através do projeto realizado, se viabiliza a possibilidade de trabalhar com softwares que originalmente não foram desenvolvidos para o trabalho pedagógico em iniciativas didáticas. Para isto, é necessário apenas um olhar diferenciado do professor para os softwares existentes e maneiras de explorá-los pedagogicamente de forma a abranger tantos conceitos quantos possíveis a disposição e interesse de nossos estudantes.

\title{
Referências Bibliográficas
}

GOOGLE, SketchUP para a educação, $2010<$ http://sketchup.google.com/intl/ptBR/industries/education.html> Acesso em 15/10/2011

HOFFMANN, Daniela S. Aprendizagem e Desenvolvimento: Experiências Físicas e Lógico-matemáticas. Texto adaptado da dissertação de mestrado Aprender matemática: tornar-se um sujeito da Sociedade em Rede, 2006. <http://www.lec.ufrgs.br/ dani/pp/dissert.htm>

MONZON, Larissa Weyh. O uso do software Google Sketchup e de material concreto para a aplicação de conceitos adquiridos nas aulas de matemática. Revista Novas Tecnologias na Educação. V. 8 No 3, dezembro, 2010

NERY, Beatriz Didonet, org; ROCHA, Silvio, org. Turma de Progressão: a inversão da lógica da exclusão. Porto Alegre: Secretaria Municipal de Educação, 1999.

PORTO ALEGRE. Secretaria Municipal de Educação de. II Congresso Municipal de Educação: teses e diretrizes. Cadernos Pedagógicos, n. 21, Porto Alegre: SMED, mar. 2000

VERGNAUD, G. Teoria dos campos conceituais. In Nasser, L. (Ed.) Anais do $1^{\circ}$ Seminário Internacional de Educação Matemática do Rio de Janeiro. p 1-26, 1993

\footnotetext{
Ciclos de Formação é uma proposta pedagógica que propõe, dentre outras coisas, reorganização curricular de forma que os alunos se mantenham organizados por idade nas turmas, que o ensino se
} 
aproxime da sua realidade, e que se diminuam os índices de evasão e reprovação escolar a partir da progressão automática dos estudantes. 